el $1.3 \%$, con un crecimiento ponderal para la década del $218 \%, 2.4$ y 4 veces menor que lo encontrado para Perú y Brasil en el mismo periodo, respectivamente. A pesar del esfuerzo, solamente el $17.4 \%$ de las referencias se publicó en revistas que tuvieron un factor de impacto promedio de 3.5, evento que ocurrió 1.6 años después de la presentación original y que permitió alcanzar 14 citas luego de su indización.

Estos datos invitan a la reflexión con la intención de generar espacios que favorezcan la calidad y visibilidad de nuestros conceptos, hallazgos relacionados con la intimidad, el fomento de la colaboración y el deseo continuo de crear una academia más generosa alrededor de las ciencias afines a la hematología y la oncología.

Los editores invitan a todos aquellos interesados en compartir el conocimiento local a incrementar la representatividad de la Asociación Colombiana de Hematología y Oncología en el entorno científico global, a través de su medio escrito, la Revista Colombiana de Hematología y Oncología.

\title{
Referencias
}

1. Saad ED, Mangabeira A, Masson AL, Prisco FE. The geography of clinical cancer research: analysis of abstracts presented at the American Society of Clinical Oncology Annual Meetings. Ann Oncol. 2010;21(3):627-32
2. Ugolini D, Mela GS. Oncological research overview in the European Union. A 5-year survey. Eur J Cancer. 2003;39(13):1888-94.

3. Rosselli-Cock D. La investigación biomédica en Colombia: un análisis de Medline. Colombia Médica. 1998;29(2-3):108-11.

\section{Ciencia y cáncer}

\section{Cancer and science}

\section{- José Félix Patiño Restrepo (Hon)*}

*Jefe Honorario, Departamento de Cirugía

Fundación Santa Fe de Bogotá

En el devenir histórico y en el avance científico de la medicina, el desarrollo de las especialidades y las subespecialidades (¿más bien superespecialidades?) constituye hitos y marca campos definidos del saber biomédico.

En las vastas y crecientes áreas de la medicina interna, la hematología y la oncología representan causas muy frecuentes de consulta. Las entidades patológicas del sistema hematolinfopoyético, benignas y malignas, afectan a todas las edades y constituyen hoy áreas de investigación, con resultados fructíferos para beneficio de los pacientes. Enfermedades, en niños y en adultos, que hasta hace pocas décadas eran incurables, hoy son tratadas en forma exitosa, con largos periodos de vida libre de enfermedad o con curación definitiva.

El desarrollo del trasplante de medula ósea, perfeccionado luego al de células progenitoras periféricas, constituye un avance de singular importancia.

Las especialidades combinadas de la oncología y la hematología se han fundido, por decirlo así, en una nueva superespecialidad, la Hemato-Oncología. La Asociación Colombiana de Hematología y Oncología $(\mathrm{ACHO})$ ha señalado áreas prioritarias en sus planes y programas de desarrollo, y desde hace años mantiene un activo y exitoso programa de generación de conocimiento.

En buena hora la $\mathrm{ACHO}$ ha decidido iniciar esta publicación, que viene a llenar un vacío en nuestro país y en los países de habla hispana. Las enfermedades que comprenden los campos de la oncología y la hematología son causa principal de morbilidad, y de mortalidad prematura -o sea la mortalidad que ocurre en niños y en adultos en las etapas productivas de la vida-, en Colombia y en América Latina.

Mantener actualizado el conocimiento es obligación para el médico, y esta nueva publicación, con una lujosa dirección editorial, se convierte en un poderoso instrumento de educación continuada y de estímulo a la investigación y la superación de la docencia. 